\title{
André Pons
}

\author{
Martin Murphy
}

Fue Blanco White quien me presentó a André Pons, hace unos veinte años. Nuestro encuentro, en la Residencia de Estudios Hispano-Americanos, marcó el principio de una amistad que ha durado hasta su muerte. A pesar de su larga enfermedad, se mantuvo tan ilusionado como siempre por embarcarse en nuevos proyectos. Su lealtad, altruismo y generosidad de espíritu son bien conocidos por todos sus amigos. Era un humanista, un amateur en el puro sentido de la palabra: alguien que disfrutaba de la búsqueda por si misma, sin pensar en el lucro o provecho personal, y que estaba siempre dispuesto a compartir sus descubrimientos. Recuerdo, también, su malicioso sentido del humor, distinguido por ese travieso brillo de los ojos que a los bretones nos gusta considerar típicamente galo. André y yo teníamos una cosa en común, aparte de nuestro afecto por Blanco: ambos fuimos principiantes tardíos. Él pronto superó esa limitación, ya que ha dejado tras de sí un corpus de trabajo que con seguridad aumentará su valor, a medida que el alcance y la novedad de sus investigaciones, la penetración de su análisis y la seguridad de su juicio sean más ampliamente valorados.

Su campo de investigación está definido por el título de su tesis seminal, publicada en 1986: Blanco White et la crise du monde hispanique, 1808-1814. Cuando comenzó, Blanco White acababa de ser recientemente resucitado y reintegrado al canon de escritores españoles como resultado de la obra de Vicente Llorens, Juan Goytisolo, Antonio Garnica y otros, pero André Pons fue el primer investigador en explorar en profundidad lo que era posiblemente el legado 
más duradero de White: su contribución, en las páginas de Semanario Patriótico y, de manera más importante, El Español, a la causa de la emancipación de la América española. América — «asunto propio mío, asunto que he identificado con mi persona»— extrajo lo mejor de Blanco. Había crecido con historias sobre América. Su tío-abuelo había sido un distinguido e ilustrado gobernador de California, y su tío, un soldado-poeta que murió joven en Louisiana, había sido un ayuda de Bernardo Gálvez. América le permitió realizar su inamovible ambición de ser útil a sus congéneres.

La tesis de Pons justifica el derecho de El Español a un puesto de honor único en la historia del periodismo español: único por la penetración de su análisis político, la fuerza elocuente de sus argumentos y la variedad y calidad de su información. Él investigó la infraestructura del periódico: su respaldo económico y la red de contactos a través de las provincias americanas que proporcionaban información, documentos y circulares. Blanco, en el centro de esta red, en Londres, jugó un papel unificador y centralizador al informar a las provincias, separadas entre sí, sobre las demás. Pero ¿qué efecto tuvo el periódico? André Pons descubrió que su influencia era sentida donde menos se esperaba. Por ejemplo, los mordaces ataques de Blanco contra el no-liberalismo de los liberales de las Cortes se los apropiaron los serviles y los incorporaron al documento que anunció el fin del gobierno constitucional: el Manifiesto de los Persas.

La seriedad de su investigación se hace evidente en la bibliografía y en los apéndices documentales con la correspondencia inédita de figuras clave como Lord Holland, Fray Servando de Mier, John Allen y Manuel Moreno. Ya antes había hecho una novedosa aportación al poner de manifiesto el papel jugado por Allen y otros colaboradores del Edinburgh Review al dar a los lectores una visión más informada de la América española. Significativamente, el primer número de El Español fue publicado exactamente el mismo mes (abril de 1810) que un artículo de Allen sobre Humboldt en el Edinburgh Review. En él Allen anticipaba la política americana más tarde adoptada por Blanco, avisando de los peligros de una prematura independencia.

Pons habría de regresar al tema de la relación de Blanco con Mier en la importante introducción biográfica que escribió para la publicación de la Historia de la Nueva España de Mier, editada por André Saint-Lu y Cécile Benassy Berling en 1990. En ella elaboró una muy necesaria y convincente pintura de los importantísimos años perdidos que Mier pasó en Londres entre octubre de 1811 y mayo de 1816. La colaboración entre Mier y Blanco fue vital para ambos. Blanco rescató a Mier (como rescató a Bello) de su aislamiento social e intelectual presentándole a sus propios amigos ingleses, como la familia del general Sir John Moore, poniéndole en contacto con editores y periodistas, y proporcionándole 
documentos para su Historia. A su vez, Mier era alguien a quien Blanco podía consultar sobre todo lo relativo a México. La colaboración entre ambos fue tanto más notable teniendo en cuenta sus opiniones divergentes sobre las ventajas de la independencia americana y el «home rule» bajo la Corona Española: su debate público sobre el tema fue una lección del democrático arte de estar de acuerdo por encima de las diferencias.

Los puntos fuertes de André Pons se aprecian mejor incluso en los artículos que escribió sobre partes menos conocidas de la obra de Blanco, como esa pequeña obra maestra, las Conversaciones americanas sobre España y sus Indias. Aquí Blanco dio con la inspirada idea de tratar la candente cuestión de la independencia americana en la forma de un diálogo dramático. Lo mismo que Joseph Conrad, en su novela Nostromo, creó una América a partir de poco más que unos recuerdos y su propia imaginación, Blanco — si parva licet componere magnispintó su escenario — «dans un village dont nous ignorerons le nom»- y sus personajes con encantadora destreza. En palabras de André Pons, «Blanco excelle dans l'art de la mise en scène. Avec une étonnante économie de moyens, il esquisse l'attitude d'un personnage, dessine une silhouette, suggère un caractère, donne à voir les gestes, recrée le mouvement». Es una lástima que Blanco no retomara el género más tarde, cuando trató el tema aún más candente de la teología.

De los cuatro interlocutores del diálogo, el cura es quien más fielmente representa las propias opiniones de Blanco sobre la cuestión americana, combinando un anticolonialismo que deriva en última instancia de Las Casas con un gradual conservadurismo aprendido de Burke. Fue este, Burke, quien curó a Blanco de su jacobinismo y fue Blanco el primero en acercarle al mundo hispánico. Esa es la tesis convincentemente argüida por André Pons en el artículo sobre «Bolívar y Blanco White» publicado en el Anuario de Estudios Americanos (1998). A través de un laborioso cotejo de textos adujo poderosas razones para evidenciar que las semillas de la conversión de Bolívar de ideólogo a pragmático fueron sembradas por Blanco, aunque sabiamente concluyó que «si El Español ejerció sobre el pensamiento de Bolívar una atracción indudable, quizás sea porque encontró en él el reflejo de ciertas de sus propias tendencias y algo que admiraba en secreto: el pragmatismo iluminado por una mente clara.» El artículo está escrito con la perspicacia y la jugosidad de estilo típicos de André Pons, ejemplificados en el siguiente epigrama: «Los dos [Bolívar y Blanco] coinciden en una idea esencial: para asumir la realidad del poder, los americanos debían tener en cuenta el poder de la realidad.»

Los tres artículos sobre «Blanco White, abolicionista» demuestran las mismas cualidades de estrecha atención al texto, exposición lúcida y lógica bañada de pasión. Estas fueron precisamente las cualidades que dieron al Bosquejo del 
comercio en esclavos (1814) del propio Blanco su capacidad no sólo para convencer la mente sino para conmover el corazón. En palabras de Pons, «El Bosquejo es una obra convincente y apasionada porque viene del corazón, y va derecha al corazón.» Su estudio de esta obra olvidada, otra pequeña obra maestra, revela su originalidad y modernidad. Blanco se anticipó a la antropología posterior al argüir que las características raciales no son fijas, sino que cambian y evolucionan como resultado de las circunstancias: la «brutalidad» de los africanos es el resultado no de su naturaleza, sino del tratamiento que reciben. Para apoyar su tesis de que todos los hombres tienen derecho a la libertad y que es un injusticia privar a nadie de ese derecho, apela no a los philosophes de la Ilustración, como podría haberse esperado, sino a una tradición anterior de humanismo cristiano derivado de Las Casas, y en último término, de Santo Tomás de Aquino. Como observa André Pons, esta philosophia perennis tenía la ventaja añadida de que era un legado compartido por todos los españoles, con independencia de su partido. Blanco, nos recuerda, había sido un poderoso predicador, y el Bosquejo debe mucho de su fuerza — su combinación de método y pasión - a las técnicas de la oratoria sagrada. Aquí Blanco encontró un tema con el que se podía comprometer sin reservas y con total convicción.

La habilidad de André Pons para introducirse en la mente de Blanco White y transmitir el espíritu de sus tiempos se debía a su talento para la empatía imaginativa. Esto es particularmente evidente en su artículo «La Seville d'un dissident» (1992), un retrato sensible y comprensivo del entorno que formó y marcó al hombre. Blanco ha sido a menudo comparado con Joyce, pero la relación de amor-odio que tuvo con su ciudad natal le recordaba a André Pons los ambiguos sentimientos de Mauriac por Bordeaux. Este estudio está basado en una lectura atenta de las Letters from Spain, y de nuevo muestra su capacidad como crítico literario. El libro ha sido visto a veces como una serie de viñetas diseñadas para complacer al lector inglés, pero Pons lo ve, en mi opinión correctamente, como un ejemplo temprano de la histoire des mentalités, cuyo objeto es «de fixer un état de moeurs à un moment de l'histoire.»

Si Blanco White fue la víctima de un siglo de injuria, como «el hombre que nunca fue» de las letras españolas, más recientemente ha sido mal servido por admiradores faltos de crítica que han intentado reinventarle a su propia imagen. André Pons procedía sobre el principio de que «tout comprendre, c'est tout [ou presque tout] pardonner,» y consiguió un raro equilibrio de honestidad y compasión. Un hombre es por supuesto mucho más que su obra, pero la obra de André Pons es un merecido monumento al hombre. ${ }^{1}$

1 Traducción de Eva Pérez Rodríguez. 


\section{La obra de André Pons}

\section{Libros}

- Blanco White et la crise du monde hispanique, 1808-1814. Thése pour le doctorat préparé sous la direction de M. Le Professeur Sain-Lu. 3 vols. Université de Paris 3, Études Hispano-Américaines, 1986.

- Blanco White y España, Oviedo, Instituto Feijoo de Estudios del Siglo XVIII, 2002.

\section{Artículos}

-, (con J.P. Clément), «Mercurio Peruano et Edinburgh Review une analyse libérale de la situation péruvienne à la veille de la guerre de l'indépendence», en Caravelle, no 31 (1978), págs. 113-133.

-, «Vision de l'Amérique espagnole par les écossais de la Edinburgh Review (1806-1811)», en Études sur l'impact culturel du Nouveau Monde. Séminaire interuniversitaire sur l'Amérique espagnole coloniale, Paris, L'Harmattan, 1981, págs. 112-128.

-, (con G. Martin Murphy), «Futher Letters of Blanco White to Robert Southney», en Bulletin of Hispanic Studies, nº 62, Liverpool, 1985, págs. 357-372.

- , «Blanco White y la oposición a las Cortes de Cádiz. Un ejemplo de recuperación política», en Bulletin d'Histoire Contemporaine de l'Espagne, $\mathrm{n}^{\circ}$ 15, Bordeaux, Maison des Pays Ibériques, 1992, págs. 41-69.

—, «La Séville d'un dissident, Blanco White», en Séville: vint siècles d'histoire: textes réunis par Bernard Lavallé, Bourdaux, Maison des Pays Ibériques, 1992, págs. 103-130.

—, «Révolution ou réforme en Amérique? Les Conversaciones americanas sobre España y sus Indias de Blanco White, El Español (1812)», en Mélanges offerts à Paul Roche. Acta Hispánica, Nantes, Université de Nantes, 1992, págs. 7995.

—, «Blanco White y la emancipación de Hispanoamérica: El Español, 18101814», en Archivo Hispalense, nº 76, Sevilla, 1993, págs. 31-52.

—, «Prensa y emancipación de Hispanoamérica: El Español, 1810-1814», en Trienio, no 24, Madrid, 1994, págs. 43-61.

-, «Blanco White, abolicionista. El Bosquexo del comercio en esclavos», en Cuadernos hispanoamericanos, nº 559, págs. 63-70; n 560, págs. 29-38; nº 565566, págs. 143-158, Madrid, 1997.

—, «Una fuente desconocida del Manifiesto de los persas, 1814: El Español de Blanco White, 1810-1814», en Trienio, n 31, Madrid, mayo 1978, págs. 79-99. 
-, «Bolívar y Blanco White», En Anuario de Estudios Americanos, nº 55, Sevilla, 1998, págs. 507-529.

\section{Obra colectiva}

—, «El contexto biográfico», en Fray Servando de Mier, en Historia de la Revolución de Nueva España, antiguamente Anahuac, ed. André Saint-Lu y Marie Cécile Bénassy-Berling (coords.), Paris, Publications de la Sorbonne, 1990, XI-XLII. 